\title{
Immunomodulatory Activity of Bioactive Fraction (PBC) from Phyllostachys bambusoides
}

\author{
Sunil Kumar ${ }^{\text {* }}$, Gaurav Sharma ${ }^{1}$, Amit Kumar ${ }^{2}$
}

\section{Sunil Kumar ${ }^{1 *}$, Gaurav} Sharma ${ }^{1}$, Amit Kumar ${ }^{2}$ 'Department of Pharmacology, School of Pharmaceutical Sciences Shoolini University Solan, Himachal Pradesh 173229, INDIA

${ }^{2}$ Indian Institute of Integrative Medicine (CSIR), Jammu 180001, Jammu and Kashmir, INDIA.

Correspondence

Sunil Kumar

Department of Pharmacology, School of Pharmaceutical, Sciences Shoolini University Solan, Himachal Pradesh 173229, INDIA

Phone no: +919736488612

E-mail: suny1435@gmail.com

History

- Submission Date: 10-06-2017;

- Review completed: 15-07-2017;

- Accepted Date: 01-08-2017

DOI : 10.5530/pj.2017.6.123

Article Available online

http://www.phcogj.com/v9/i6

Copyright

(c) 2017 Phcog.Net. This is an openaccess article distributed under the terms of the Creative Commons Attribution 4.0

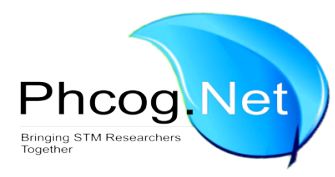

\begin{abstract}
Background: The lack of vaccines and limitations of currently available strategies demand a need to develop safe and efficacious immunomodulators. Phyllostachys bambusoides is traditionally used for various autoimmune and infectious disorders, a property possibly attributable to presence of flavonoids like orientin and iso-orientin. Objective: the objective of this study was, to search a potent immunomodulator which elicit both Th1 and Th2 immune response. Methods: The animals were $(\mathrm{Balb} / \mathrm{c})$ treated with the bioactive fraction (PBC) from P. bambusoides (100 and $200 \mathrm{mg} / \mathrm{kg}$ body weight) for 14 days with SRBC (Sheep Red Blood Cells) as an antigen. Haemagglutination antibody (HA) titre, delayed type hypersensitivity (DTH) reaction, phagocytic index, NO production, analysis of cytokines in serum and CD80/ CD86 population in spleen. Results: PBC significantly enhanced the expression of IgM and IgG titre and DTH response in a dose dependant manner after 24 and $48 \mathrm{~h}$ in BALB/c mice with a maximum response at $200 \mathrm{mg} / \mathrm{Kg}$. Besides humoral and cell mediated immunity, it also enhanced phagocytic index, nitric oxide production, which further leads to protection against Candida albicans infection. It also, enhanced the expression of CD80 and CD86 in splenic cells. Conclusion: Taken together these in vitro and in vivo data, our results suggest that PBC acts as an effective immunostimulator which specially enhances macrophage function during infection. This further supports the role of PBC in immunopharmacologic applications. Key words: Macrophages, Immunostimulation, Phyllostachys bambusoides, Ha Titre, Cytokine.
\end{abstract}

\section{INTRODUCTION}

The modulation of the immune response to alleviate the disease has been of great interest for many years. Currently, the plant based immunomodulators are receiving inadequate attention. Many synthetic and natural plant products have been evaluated for their immunomodulatory potential. Plant and animal materials have been used successfully for the treatment of human diseases since ancient times. In Indian system of medicine, a wide range of drugs from natural origin have been advocated for a variety of diseases. ${ }^{1}$ Ayurveda is one of the traditional system of medicine practiced in Sri Lanka \& India, and can be find back to $6000 \mathrm{BC}$. Modulation of immune responses to alleviate the diseases has been of interest for many years and the concept of 'Rasayana' in Ayurveda is based on related principles. Immunostimulation in a drug-induced immunosuppression model and immunosuppression in an experimental hyper-reactivity model by the same preparation can be said to be true immunomodulation. ${ }^{2}$ Apart from being specifically stimulatory or suppressive, certain agents have been shown to possess activity to normalize or modulate pathophysiological processes and are hence called immunomodulatory agents. ${ }^{3}$

P. bambusoides represents a remarkable reputation among the indigenous system of medicine and modulates the biologic response of immune cells that enhance the host's ability to resist infections. Mainly it has been used in Chinese medicine for diarrhea, inflammation, stomachache, and restlessness. ${ }^{4}$ The various phytochemical studies shown that bamboo is a rich source of flavonoids. ${ }^{5}$ Among the various flavonoids present in P. bambusoides, orientin seems to be of pivotal importance for its antioxidant property. ${ }^{6}$ It is reported that orientin, in combination with other bioactive molecules may have a potential immunomodulatory properties. ${ }^{7}$ Also, the plant is already reported for antioxidants, ${ }^{8}$ antipyretic, analgesic, anticonvulsant, ${ }^{9}$ and anti-inflammatory activity. ${ }^{10}$

On the basis of the importance of leaves for immunological aspects, various fractions were prepared from the whole alcoholic extract and subjected for preliminary study. The most active fraction (PBC) was subjected for a panel of in vivo assay to evaluate its immunomoduatory property. The HPLC fingerprinting revealed the presence of the compound of our interest, orientin (Figure 1). It is well known that the agents which are capable of modulating the immune response, treat or prevent immune based disorders. ${ }^{11}$ Such agents may increase the antibody responses, or act by modifying the cell mediated immune response. By characterizing the immunological 
correlates, such measurements will aid in the development of prophylactic drugs.

\section{MATERIAL AND METHODS}

\section{Reagents}

Methanol was purchased from Qualigens, Mumbai, medium RPMI 1640 (Himedia, Bombay, India), fetal calf serum (FCS) (Gibco, USA), trypan blue (Microlabs, Bombay), $96 \mathrm{~V}$ wells micro titration plates and micro tissue culture plates (96 U wells) from Tarson, , Concanavalin-A (Con-A), lipopolysaccharide (LPS), dimethylsulphoxide (DMSO), streptomycin, penicillin, levamisole and MTT (3- [(4,5-dimethylthiazol-2yl)2,5-diphenyltetrazolium bromide) from Sigma were used.

\section{Plant materials}

The fresh leaves of $P$. bambusoides were collected from the herbal garden of University of Horticulture and Forestry, Nauni, Solan, India. A voucher specimen (UHF/12530) has been deposited the Department Forestry products, Nauni University.

\section{Preparation of extract and Isolation}

The powdered plant material $(1 \mathrm{Kg})$ was subjected to continuous hot percolation process using Soxhlet apparatus with methanol at room temperature. After exhaustive extraction, the extract was concentrated under vacuum at $50-55^{\circ} \mathrm{C}$. Extract was dissolved in $5 \% \mathrm{HCl}$ and filtered. Filtrate was treated with chloroform and ethyl acetate respectively in a separating funnel to obtain non-alkaloidal chloroform and ethyl acetate fraction. The chloroform fraction was subjected to silica gel (60-120 mesh) column chromatography. The column was eluted using a gradient of hexane-ethyl acetate (100:0-0:100) to afford 76 fractions. All the fractions were checked on TLC, spots were visualized under UV chamber. Out of 76 fractions, based on TLC pattern 5 broad fraction were prepared and again most bioactive fraction was subjected for repeated column chromatography using same solvent system and 23 fractions were eluted. Out of 23 fractions, four fraction-3-7 (eluted in 15\% hexane-ethyl acetate), showed one major spot in TLC. These four fractions were pooled (PBC) and subjected for a panel of in vivo assay. The fraction was standardised using HPLC shown in Figure 1.

\section{Animals}

Study was conducted on male Balb/c mice (18-22 g, four to six week old). The ethical committee of the CSIR Jammu, approved all protocols. The animals were maintained under standard conditions: temperature $\left(25 \pm 2{ }^{\circ} \mathrm{C}\right)$ and photoperiod of $12 \mathrm{~h}$. Commercial pellet diet (Ashirwad Industries, Chandigarh, India) and water were given ad libitum. All animals used in experimental work received human care.

\section{Immunization schedule}

The blood was withdrawn from Jugular vein of the sheep in Alsever's solution. ${ }^{12}$ The SRBCs were washed thrice with pyrogen free saline and a suspension of $5 \times 10^{9} \mathrm{cells} / \mathrm{mL}$ was prepared for immunization. Mice were divided into four groups, each consisted of six animals. PBC 100 and $200 \mathrm{mg} / \mathrm{Kg}$ (in $200 \mu \mathrm{L}$ of $1 \%$ gum acacia) was administered orally for 14 days, daily. The volume of dose was $200 \mu \mathrm{L}$. Control group received $1 \%$ gum acacia. Levamisole $(2.5 \mathrm{mg} / \mathrm{Kg}$ body weight $)$ was given orally as a positive control. On day 0 all animals were immunized with $200 \mu \mathrm{L}$ of SRBC $\left(5 \times 10^{9}\right)$ per mouse intraperitoneally (i.p.). Additionally immunized groups were challenged on day 7 with SRBC, used for DTH assay.

\section{Anti-SRBC antibody titre and Delayed type hypersensitivity (DTH) reaction in mice}

The most active Anti-SRBC circulating antibody (IgM and IgG) titers of mice were determined by haemagglutination titre. Blood samples were collected from individual animals, from retro-orbital plexus on day 7 and 14 for primary \& secondary antibody titre respectively. The antibody levels were determined in serum by the haemagglutination technique. ${ }^{13}$ For DTH PBC was administered $2 \mathrm{~h}$ after immunization and once daily for six days. The thickness of the right hind footpad was considered as the control and was measured with a spheromicrometer (pitch, $0.01 \mathrm{~mm}$ ). The mice were then challenged by injecting $20 \mu \mathrm{L}$ of $5 \times 10^{9} \mathrm{SRBC} / \mathrm{mL}$ into the left hind footpad (intradermally). The thickness of footpad was measured again after 24 and $48 \mathrm{~h}^{14}$

\section{In vitro phagocytic activity of peritoneal macrophages}

The effect on phagocytic activity of normal peritoneal macrophages was evaluated by utilizing C. albicans. The phagocytic function of peritoneal macrophages was assessed by the method of Lehrer (1981). The resident peritoneal macrophages of mice were harvested by flushing the peritoneal cavity with $5 \mathrm{ml}$ of RPMI. The cells $\left(2 \times 10^{6}\right)$ from the suspension were allowed to adhere to glass cover slips $(22 \times 22 \mathrm{~mm})$ for $2 \mathrm{~h}$ in $\mathrm{CO}_{2}$ incubator in absence or presence of different concentrations of PBC. The cover slips were then washed thoroughly with PBS to remove nonadherent cells. During this period, heat-killed $\left(100{ }^{\circ} \mathrm{C}, 30 \mathrm{~min}\right)$ Candida cells were opsonized for 90 min with $20 \%$ mouse serum. Hundred microliters $(100 \mu \mathrm{l})$ of opsonized candida $\left(2 \times 10^{9}\right.$ cells $\left./ \mathrm{ml}\right)$ cells were then spread over the monolayer and the mixture was again incubated for $15 \mathrm{~min}$. in $\mathrm{CO}_{2}$ incubator. At the end of this period, the cover slips were washed thoroughly with PBS and stained with Trypan-eosin. The samples were immediately evaluated microscopically to determine the number of yeast cells ingested per cell (phagocytic index). At least 100 adherent cells were evaluated per sample, the phagocytic index were calculated. ${ }^{15}$

\section{In vitro NO production assay}

A volume of $10 \mathrm{~mL}$ of ice cold RPMI was injected into fresh Balb/c mice. After proper lavage, the medium was taken out using same syringe and centrifuged at $1800 \times \mathrm{g}$ for $10 \mathrm{~min}$ at $4^{\circ} \mathrm{C}$. The pellet was re-suspended in RPMI medium and macrophages $\left(3 \times 10^{6}\right)$ were seeded in 96-well culture plate with different concentration of PBC and incubated for $18 \mathrm{~h}$. After incubation $100 \mu \mathrm{L}$ of supernatant was transferred to another plate in the same fashion and $100 \mu \mathrm{L}$ of Griss reagent ( $1 \%$ sulfanilamide, $0.1 \%$ naphthylethylene diamine in $2.5 \%$ phosphoric acid) was added. The plate was read at $540 \mathrm{~nm} .{ }^{16}$

\section{Determination of IFN- $\gamma$ and IL-4 by ELISA and Phenotypic analysis of (CD80 and CD86) co-stimulatory molecules by flow cytometry}

Serum was collected $4 \mathrm{~h}$ after final oral administration of the PBC. The IFN- $\gamma$ and IL- 4 were measured with an enzyme linked immunosorbent assay (ELISA kit, R\&D Systems Quantikine) according to the instructions of the manufacturer. ${ }^{17}$

For phenotypic analysis, splenic cells from $\mathrm{PBC}$-treated $\mathrm{BALB} / \mathrm{c}$ were suspended in RPMI media after removing the RBCs by RBC lysis buffer. Cells $\left(1 \times 10^{7}\right.$ cells $\left./ \mathrm{mL}\right)$ were washed and incubated for $1 \mathrm{~h}$ at $37^{\circ} \mathrm{C}$. To measure the expression of co-stimulatory molecules, the cells were stained with FITC-labeled anti-CD80 and anti-CD86 mAbs. The data were analyzed for ten thousand cells with FACScan flow cytometer. ${ }^{18}$ 


\section{Statistics}

Data were expressed as mean $\pm \mathrm{SEM}$, and statistical analysis was carried out using Bonferroni correction multiple comparison test (One way ANNOVA). All in vitro experiments were carried out in triplicates and represented as mean \pm SEM. P values $<0.05$ were being taken as statistically significant.

\section{RESULTS}

\section{HPLC fingerprinting of PBC}

The HPLC chromatogram of PBC is shown in Figure 1. It showed 8 peaks with varying retention times $(2.40,6.27,9.60,11.92,13.63,14.20,16.29$, 19.63 ,) including the presence of iso-orientin (11.92); orientin (13.63).

\section{Effect of PBC on anti-SRBC antibody titre and DTH response}

Bioacive fraction PBC (100-200 mg/Kg, p.o.) produced a dose-related increase in the primary and secondary antibody synthesis and also showed the significant cell-mediated immunity in terms of the footpad thickness, expressed as DTH reaction given in Table 1.

\section{Effect of PBC on phagocytic activity}

A highly significant increase in phagocytic index was obtained at $50 \mu \mathrm{g}$ (Figure 2). PBC caused a dose dependent increase in phagocytic index as compared with control group.

\section{Effect of PBC on nitrite content}

The effect of $\mathrm{PBC}$ on production of $\mathrm{NO}$ was observed in peritoneal macrophages isolated from $\mathrm{Balb} / \mathrm{c}$ mice. $\mathrm{PBC}$ showed a dose dependent increase in nitrite content as compared to the control group (Figure 3).

\section{Effect of PBC on IFN- $\gamma$ and IL-4 and on the expression of CD80 and CD86 in mice}

PBC significantly up-regulated Th1 (IFN- $\gamma$ ) and Th2 (IL-4) cytokines compared to the control group (Figure 4a); a similar trend was observed in expression of CD80 and CD86 at 100 and $200 \mathrm{mg} / \mathrm{Kg}$ (Figure 4b).

\section{DISCUSSION}

The integrity of immune response along with other factors, depends on the involvement of molecular communication through release of chemical mediators and its interaction with T \& B cells. There are three types of cells which modulate the immune response and these include T \& B lymphocytes and macrophages. ${ }^{19}$ Now a day, the demand for drugs having potential for enhancing both specific and non-specific immune response is increasing continuously. Therefore the focus of the present study was to investigate in depth, the role of macrophages stimulated by $\mathrm{PBC}$ in host defense mechanism.

In the present study, immunomodulatory effect of $\mathrm{PBC}$ were established in $\mathrm{BALB} / \mathrm{c}$ mice employing a panel of in vitro, in vivo and ex vivo assay models. Orientin is the principle bioactive compound present in PBC thus it may be suggested that orientin might be responsible for immunomodulatory potential shown in the present study. These results are in agreement with the previously published report. ${ }^{7}$ The antibody response was observed by HA titre using SRBC as an antigen and found increased number of IgM and IgG antibodies. The augmentation of IgM and IgG production in response to SRBC is due to increased responsiveness of macrophages because macrophages are closely associated with production of antibodies. Further, T cells contribute to delayed type of hypersensitivity reaction via participating in the expression of cell mediated immunity. ${ }^{20}$ $\mathrm{PBC}$ enhances the delay type hypersensitivity reaction compared to control group, as reflected by increased in footpad thickness and it revealed that macrophages in-filtered at inflammatory sites. ${ }^{21,22}$

The effect of $\mathrm{PBC}$ on the non-specific defence mechanism were determined. Since Macrophages and granulocytes play an important role in non-specific defence therefore in vitro phagocytic function was performed. In the present result we assessed the phagocytic function of macrophages by ingestion of candida particles in PBC treated macrophages. Results revealed that $\mathrm{PBC}$ enhances the non-specific immune response. Moreover, Th1 and Th2 cytokines have an important role in both adaptive and innate immunity. ${ }^{23}$ They are the major components involved in regulation of the immune mechanism to antigens and infectious agents. IFN- $\gamma$, a type of Th- 1 cytokines are capable of inducing the generation of macrophages and $\mathrm{T}$ cells, while Th- 2 cytokine up-

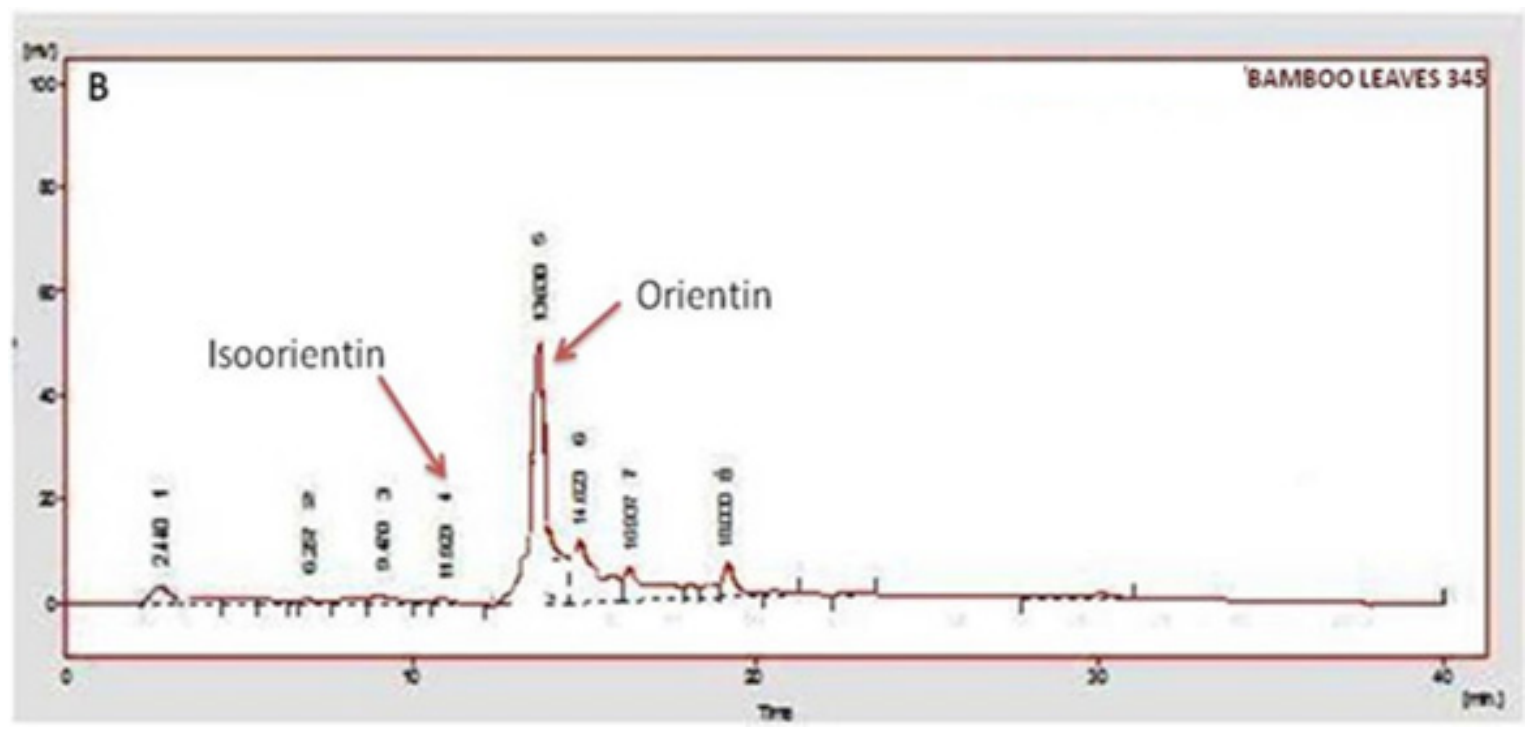

Figure 1: HPLC fingerprinting of PBC showing presence of orientin (13.63) and isoorientin (11.92) at different Rt. The separation was carried out Eclips XBD C18 column, $4.6 \times 150 \mathrm{~mm}, 5 \mu \mathrm{m}$ particle size, and the temperature was maintained at $25^{\circ} \mathrm{C}$. 


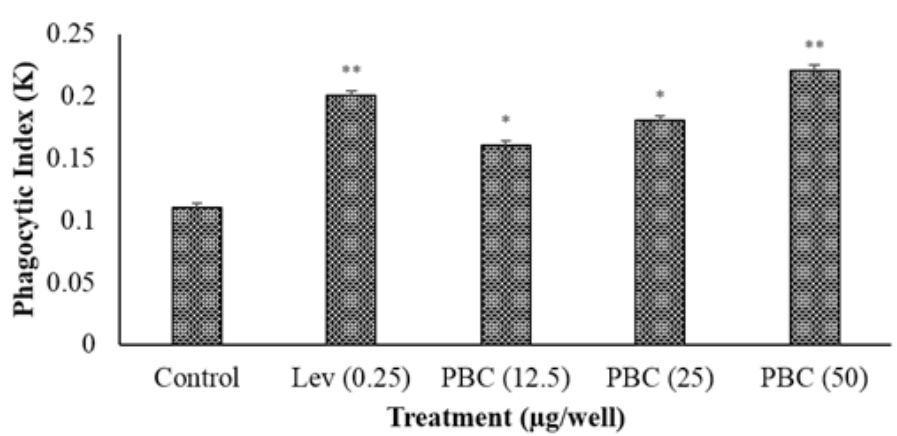

Figure 2: Phagocytic index was calculated in murine macrophage induced by different concentration of PBC PBC $(12.5,25$ and $50 \mu \mathrm{g} /$ well). Data are mean \pm S.E. of five animals. ${ }^{*} p<0.05$ and ${ }^{* *} p<0.01$ compared with control group.

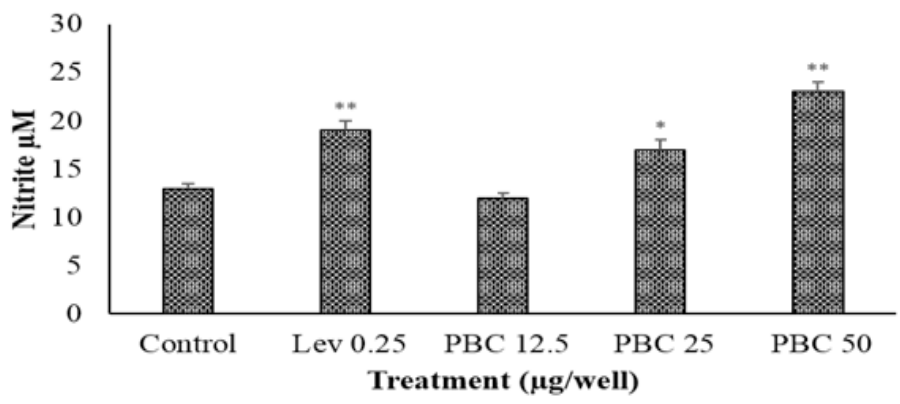

Figure 3: Peritoneal macrophages $\left(3 \times 10^{6}\right.$ cell $\left.\mathrm{s} / \mathrm{mL}\right)$ were cultured with different concentration of PBC (12.5, 25 and $50 \mu \mathrm{g} /$ well) for $18 \mathrm{~h}$. Results are expressed in $\mu \mathrm{M}$. Data are mean \pm S.E. of six animals. ${ }^{*} p<0.05$ and ${ }^{* *} p<0.01$ compared with control group.

(a)

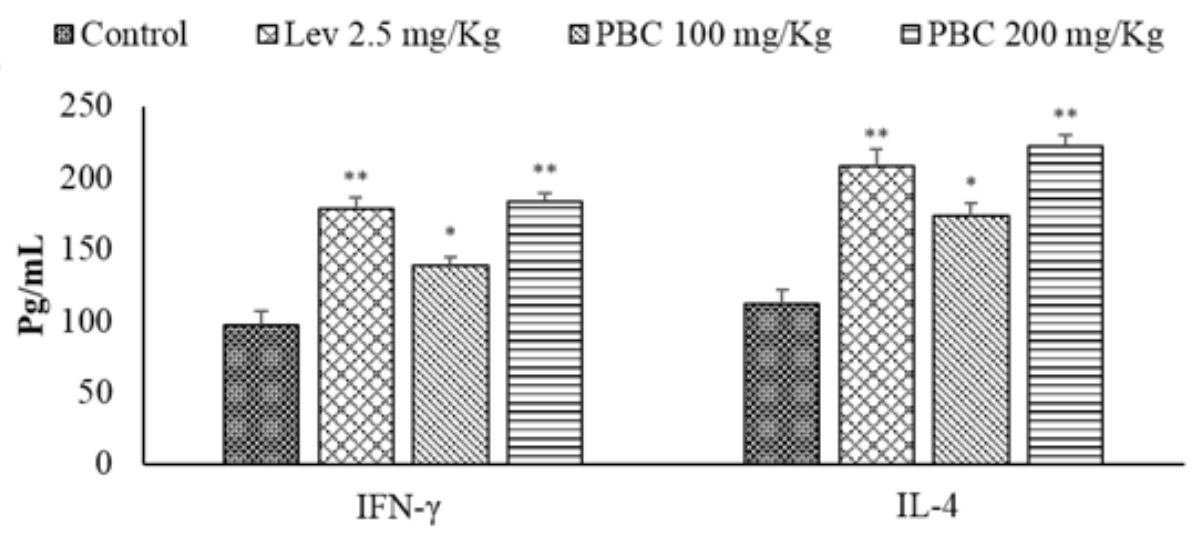

(Cytokine)

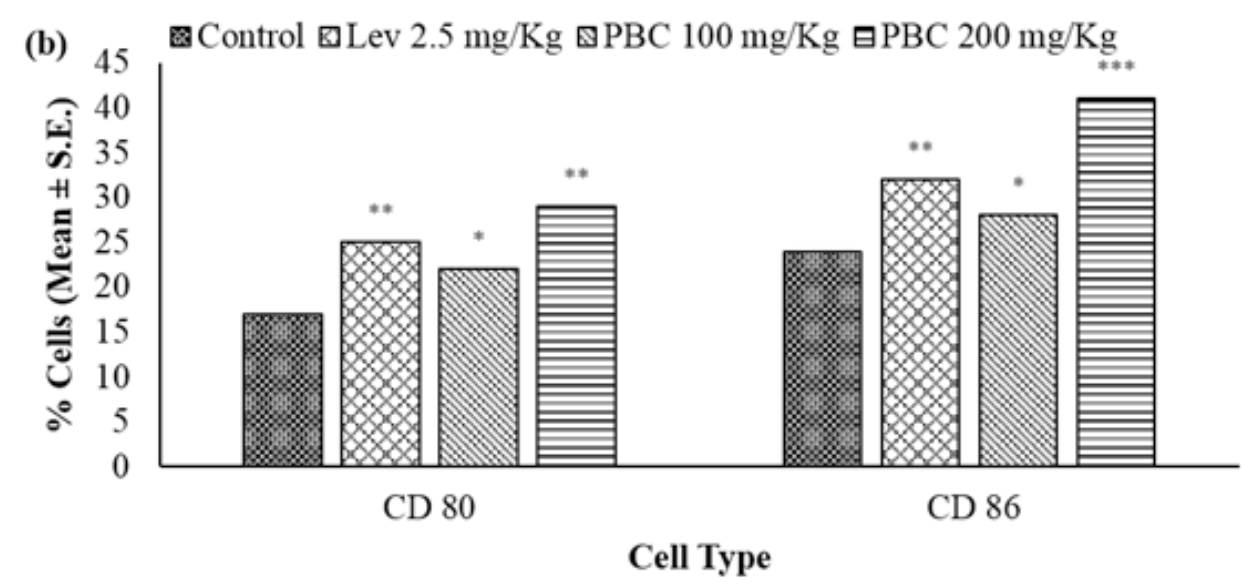

Figure 4: (a) Influence of PBC on the cytokines (IFN- $\gamma$ and IL-4) expression on mouse serum collected on day 14 after immunization. (b) The expression of CD80/CD86 molecules in splenic macrophages. Values are means $\pm \mathrm{SE} ;{ }^{*} \mathrm{p}<0.05,{ }^{* *} \mathrm{p}<0.01$, and ${ }^{* * *} \mathrm{P}<0.001$ (control vs. PBC-treated groups; using one-way ANOVA).

regulation id directly correlated with phagocytic potential, since it leads to generation of superoxide and NO production. ${ }^{24}$ In PBC treated groups, Th-1 (IFN- $\gamma$ ) was found to be up along with an increase in the level of Th-2 (IL-4) cytokine. It was also observed that PBC augmented the release of nitric oxide (in vitro). The results presented here show that PBC may stimulate the immune function of macrophages through up-regulation of IFN- $\gamma$, IL-4 and NO production.
Further, co-stimulatory signals play important role in the delivery of the required immune response through the cell-cell cross talk. CD80 and CD86 have been found essential in maintaining the state of immune response and in maintaining the immune memory respectively. ${ }^{25}$ The PBC treated mice showed a significantly enhanced expressions of CD 80 and CD86 in splenic macrophages, supporting its potential to activate the antigen presenting cells. $\mathrm{PBC}$ up-regulates the co-stimulatory bio- 
Table 1: Effect of PBC on HA titre and DTH response

$\begin{array}{cccccc}\text { Treatment } & \begin{array}{c}\text { Dose }(\mathrm{mg} / \\ \mathrm{Kg})\end{array} & \begin{array}{c}\text { Primary } \\ \text { antibody titre }\end{array} & \begin{array}{c}\text { Secondary } \\ \text { antibody titre }\end{array} & \begin{array}{c}\text { DTH response after } \\ \mathbf{2 4 h} \mathbf{h}\end{array} & \begin{array}{c}\text { DTH response after } \\ \mathbf{4 8} \mathrm{h}\end{array} \\ \text { Control } & - & 6.2 \pm 0.4 & 5.8 \pm 0.4 & 1.74 \pm 0.06 & 1.62 \pm 0.04 \\ \text { Levamisole } & 2.5 & 8.4 \pm 0.6^{*} & 7.8 \pm 0.4^{*} & 2.32 \pm 0.08^{* *} & 2.14 \pm 0.04^{*} \\ \text { PBC } & 100 & 7.8 \pm 0.4^{*} & 7.2 \pm 0.4^{*} & 2.16 \pm 0.08^{*} & 2.02 \pm 0.02^{*} \\ \text { PBC } & 200 & 9.6 \pm 0.4^{* *} & 8.8 \pm 0.6^{* *} & 2.54 \pm 0.04^{* *} & 2.22 \pm 0.04^{* *}\end{array}$

Data are mean \pm S.E. of six animals. ${ }^{*} \mathrm{P}<0.05$ and ${ }^{* *} \mathrm{P}<0.01$ compared with control group.

molecules by secreting various cytokines and chemokine which further helps in the generation of effective immune response. In conclusion it may be suggested that immunomodulatory effect of $\mathrm{PBC}$ are at least in part due to presence of orientin. We further emphasise that orientin might be effective in nursing the diseases where the underlying defect is a phagocytic dysfunction as it enhances the immune response by improving the function of phagocytic cells. However more studies are required to reinforce the fact.

\section{CONCLUSION}

In conclusion, $\mathrm{PBC}$ from $P$. bambusoides displayed immunomodulating potential by increasing haemagglutination antibody titre, DTH response, phagocytic activity and also enhanced cytokine production \& CD80/ CD86 expression. Taken together, these results suggest that it could be a drug of choice, effective in treating the diseases where the underlying defect is a T-cell and B-cell deficiency or phagocytic dysfunction.

\section{ACKNOWLEDGEMENT}

Authors appreciated Shoolini University, Himachal Pradesh for providing all the required conveniences.

\section{CONFLICT OF INTEREST}

Authors declare that there is no conflict of interest, financial or otherwise.

\section{ABBREVIATION USED}

MTT: 3-(4,5-di-methylthiazol- 2-yl)-2,5-diphenyltetrazolium bromide; CTL: Cytotoxic T lymphocytes; LC: Liquid chromatographyIL-2: Interleukin-2; IL-4: Interleukin-4; IFN- $\gamma$ : Interferon- $\gamma$; DTH: Delay Type Hypersensitivity.

\section{REFERENCES}

1. Brekhman II, Dardymov IV. New substances of plant origin which increase nonspecific resistance. Annual review of pharmacology.1969;9(1):419-30

2. Patwardhan B, Kalbag D, Patki PS, Nagasampagi BA. Search of immunomodulatory agents--A review. Indian Drugs. 1990;28:348-58.

3. Wagner $\mathrm{H}$. Search for plant derived natural products with immunostimulatory activity (recent advances). Pure Appl Chem. 1990;62(7):1217-22

4. Zhang $Y$, Wu X, Ren Y, Fu J, Zhang Y. Safety evaluation of a triterpenoid-rich extract from bamboo shavings. Food Chem Toxicol. 2004;42(11):1867-75.

5. Kumar S, Sharma G, Sidiq T, Khajuria A, Jain M, Bhagwat D, et al. Immunomodulatory potential of a bioactive fraction from the leaves of Phyllostachys bambusoides (Bamboo) in BALB/C mice. EXCLI journal. 2014;13:137.

6. Hassan EM, Matloub AA, Aboutabl ME, Ibrahim NA, Mohamed SM. Assessment of anti-inflammatory, ant nociceptive, immunomodulatory, and antioxidant activities of Cajanus cajan L. seeds cultivated in Egypt and its phytochemical composition. Pharm Biol. 2015;53:1-12.
7. Mukherjee PK, Nema NK, Bhadra S, Mukherjee D, Braga FC, Matsabisa MG Immunomodulatory leads from medicinal plants. Indian J Tradit Know. 2014; 13:235-56.

8. Mu J, Uehara T, Li J, Furuno T. Identification and evaluation of antioxidant activities of bamboo extracts. Forest Stud China. 2004;6:1-5.

9. Kumar S, Sharma G, Sharma A, George M, Joseph L. Anticonvulsant activity of chloroform extract of Phyllostachys bambusoides. Int J Pharm Pharm Sci. 2011;3(5):125-7.

10. Kim L, Potts R, Eeuwes C, Dominic A, Nevis I, Kim HL. Measured depth of subcutaneous tissue on posterolateral arm of aeroallergen immunotherapy patients. Allergy, Asthma \& Clinical Immunology. 2012;8(1):A7.

11. Camacho LH. Novel therapies targeting the immune system: CTLA4 blockade with tremelimumab (CP-675,206), a fully human monoclonal antibody. Expert opinion on investigational drugs. 2008;17(3):371-85.

12. Alsever JB, Ainslie RB. A new method for the preparation of dilute blood plasma and the operation of a complete transfusion service. NY State J. Med. 1941:41:126-31.

13. Gupta A, Khajuria A, Singh J, Bedi KL, Satti NK, Dutt P, et al. Immunomodulatory activity of biopolymeric fraction RLJ-NE-205 from Picrorhiza kurroa. International immunopharmacology. 2006;6(10):1543-9

14. Bafna AR, Mishra SH. Protective effect of bioactive fraction of Sphaeranthus indicus Linn. Against cyclophosphamide induced suppression of humoral immunity in mice. Journal of ethno pharmacology. 2006:104(3):426-9.

15. Lehrer RI. Ingestion and destruction of Candida albicans. In: Adams DO, Edelson PJ, Koren $\mathrm{H}$, editors. Methods for studying mono-nuclear phagocytes. Academic Press: New York. 1981:693-708.

16. Green LC, Wagner DA, Glogowski J, Skipper PL, Wishnok JS, Tannenbaum SR. Analysis of nitrate, nitrite, and $[15 \mathrm{~N}]$ nitrate in biological fluids. Analytical biochemistry. 1982;126(1):131-8.

17. Beutler B, Cerami A. The biology of cachectin/TNF--a primary mediator of the host response. Annual review of immunology. 1989;7(1):625-55.

18. Khan S, Malik F, Suri KA, Singh J. Molecular insight into the immune up-regulatory properties of the leaf extract of Ashwagandha and identification of Th1 immunostimulatory chemical entity. Vaccine. 2009;27(43):6080-7.

19. Radov LA, Kamp D, Trusso LA, Sloane D, Julien RP, Clemens CM, et al. The immunological profile of a new immunomodulatory agent, oxamisole. International journal of immunopharmacology. 1988;10(5):609-18.

20. Góngora L, Máñez S, Giner RM, Recio MC, Ríos JL. On the activity of trifluoperazine and palmitoylcarnitine in mice: delayed hypersensitivity models. Life sciences. 2000;66(14):PL183-8.

21. Benacerraf B. A hypothesis to relate the specificity of $T$ lymphocytes and the activity of I region-specific Ir genes in macrophages and B lymphocytes. J Immunol. 1978;120:1809-12.

22. Resto-Ruiz S, Burgess $A$, Anderson BE. The role of the host immune response in pathogenesis of Bartonella henselae. DNA and cell biology. 2003;22(6):431-40.

23. Billiau A, Heremans $H$, Vermeire K, Matthys P. Immunomodulatory properties of interferon- $\gamma$ : an update. Ann NY Acad Sci. 1998;856:22-32.

24. Stichtenoth DO, Frölich JC. Nitric oxide and inflammatory joint diseases. British journal of rheumatology. 1998;37(3):246-57.

25. Girvin AM, Dal Canto MC, Rhee L, Salomon B, Sharpe A, Bluestone JA Miller SD. A critical role for B7/CD28 costimulation in experimental autoimmune encephalomyelitis: a comparative study using costimulatory moleculedeficient mice and monoclonal antibody blockade. The Journal of Immunology. 2000;164(1):136-43 


\section{GRAPHICAL ABSTRACT}

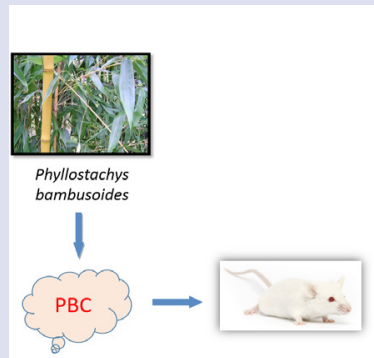

\section{ABOUT AUTHORS}

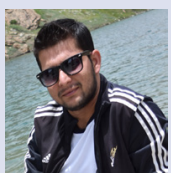

Dr Sunil Kumar: Is working as an Assistant Professor in School of Pharmaceutical Sciences, Shoolini University. His area of research is focused on immunology and immunomodulation mediated anticancer activity.

Cite this article: Kumar S, Kumar A. Immunomodulatory Activity of Bioactive Fraction (PBC) from Phyllostachys bambusoides. Pharmacog J. 2017;9(6):786-91. 